Research, Society and Development, v. 9, n. 11, e1289119665, 2020

(CC BY 4.0) | ISSN 2525-3409 | DOI: http://dx.doi.org/10.33448/rsd-v9i11.9665

Tornar-se professor: o entrelaçamento das dimensões pessoais, profissionais, institucionais e relacionais

Becoming teacher: the lathing of personal dimensions, professional, institutional and relational

Hacerse profesor: el cruce de las dimensiones personales, profesionales, institucionales y relacionales

Recebido: 26/10/2020 | Revisado: 30/10/2020 | Aceito: 04/11/2020 | Publicado: 06/11/2020

Edson Gomes Evangelista

ORCID: https://orcid.org/0000-0002-2092-533X Instituto Federal de Educação, Ciência e Tecnologia de Mato Grosso, Brasil E-mail: edson.evangelista@blv.ifmt.edu.br Luciane de Almeida Gomes ORCID: https://orcid.org/0000-0002-1325-1373 Instituto Federal de Educação, Ciência e Tecnologia de Mato Grosso, Brasil E-mail: lualgomes@hotmail.com

\title{
Resumo
}

O presente texto consiste em um ensaio que cruza as trajetórias de dois profissionais da Educação que se encontram no Programa de Pós-Graduação em Educação em nível de doutorado/PPGE/UFMT, no curso da disciplina de Docência no Ensino Superior, e encontram em suas trajetórias a justificativa para suas intenções de pesquisa. Com fulcro no referencial do Desenvolvimento profissional docente, decidem escrever juntos, as respectivas histórias. É importante considerar que as reflexões que fazem sentido nesse texto ganham corpo a partir do entrelaçamento das histórias de vida, dos respectivos percursos de pesquisa e do reconhecimento da pesquisa como espaço de formação. $\mathrm{O}$ texto parte das histórias de vida dos pesquisadores, busca levantar os elementos reflexivos nos percursos de pesquisa, revelando os pontos que se constituem aspectos formativos dessa construção. Assim, este ensaio procura evocar a partir das histórias contadas que não nascemos professores, vamos nos fazendo professores ao longo de uma vida.

Palavras-chave: História de vida; Pesquisa em educação; Desenvolvimento profisssional. 


\begin{abstract}
This text consists of a test that crosses the paths of two education professionals who are in the Graduate Program in Education at the doctoral level / PPGE / UFMT, in the course of Teaching discipline in higher education, and are in their trajectories the rationale for their research intentions. With fulcrum in the frame of teacher professional development, decided to write together, their stories. It is important to consider that the reflections that make sense in this text take shape from the interweaving of life stories, of their research paths and recognition of research and training space. The text of the life stories of the researchers, seeks to raise the reflective elements in search paths, revealing the points that are formative aspects of construction. Thus, this essay seeks to evoke from the stories that were not born teachers, we become teachers over a lifetime.
\end{abstract}

Keywords: Life history; Research in education; Professional development.

\title{
Resumen
}

Esto es un ensayo que presenta el cruce de las trayectorias de dos profesionales de la Educación, los cuales se encuentran en el Programa de Pos-graduación del curso de Doctorado en Educación, en la asignatura Docencia en la Enseñanza Superior. Perciben que sus investigaciones se relacionan con sus trayectorias. Basados en el referencial del Desarrollo Profesional Docente, escriben sus respectivas historias. Las reflexiones presentadas en el texto resultan del cruce de las historias de vida, de los percusios de investigación y del reconocimiento de la investigación como espacio de formación. El ensayo se desarrolla a partir de las historias de vida de los dos investigadores, intenta alcanzar los aspectos que provocan las reflexiones en estos percusios de investigación, revela los aspectos formativos en esta construcción. Total que, esto ensayo basado en nuestras historias revela que no nacimos profesores, vinimos nos haciendo docentes a lo largo de una vida.

Palabras clave: Historia de vida; Investigación en educación; Desarrollo profesional.

\section{Histórias de Vida}

As histórias de vida aqui contadas, de pesquisadores que decidem pelo percurso de pesquisa junto a professores da Educação Básica se fazem a partir do questionamento de Nóvoa (1995, p.16): “Como é que cada um se tornou no professor que é hoje? De que forma a ação pedagógica é influenciada pelas características pessoais e pelo percurso de vida profissional de cada professor?" 
Afinal,

Falar da carreira docente, não é mais do que reconhecer que os professores, do ponto de vista do "aprender a ensinar", passam por diferentes etapas (pré-formação, formação inicial, iniciação e formação permanente, de acordo com Feiman, 1983), as quais representam exigências pessoais, profissionais, organizacionais, contextuais, psicológicas, et., específicas e diferenciadas. (Marcelo, 2013, p. 12)

Os pesquisadores aqui anunciados desenvolveram as respectivas trajetórias como professores da Educação Básica na rede estadual de ensino de Mato Grosso, e também tiveram os percursos marcados pela atuação nos CEFAPROS (Centro de Formação e Atualização dos Profissionais da Educação), ambos como Formadores da área de Linguagens, trajetórias construídas pelo reconhecimento da escola como espaço de formação. Podemos perceber encontros e distanciamentos em suas trajetórias profissionais.

Seguindo as trajetórias individuais, um dos pesquisadores passa a atuar como professor de linguagens no Instituto Federal de Educação, Ciência e Tecnologia de Mato Grosso a partir de meados de 2012, outra como docente do Ensino Superior na Faculdade de Educação Física da UFMT, nas disciplinas de Teoria e Prática no Ensino Fundamental e Estágio Curricular no Ensino Fundamental a parir do final e 2012.

Marcados por infâncias absolutamente diferentes, um filho de produtor rural, encaminhado à escola aos 7 anos, entendendo o desejo dos pais de que a vida do campo não era intencionada como destino, outra, filha de professora, com uma infância privilegiada do ponto de vista econômico e social, frequentou escola sempre, acompanhando a mãe em seu local de trabalho.

Essas diferenças marcam todo o percurso escolar dos pesquisadores, um estudante de "segundo grau" público, jovem trabalhador, outra concluiu em uma boa escola privada, curso "propedêutico", sendo toda sua juventude direcionada aos estudos.

Concluído o segundo grau, Ensino Médio, um dos pesquisadores após uma tentativa pouco exitosa de ingressar no Curso de História na UFMT, recebeu uma carta de seu pai na qual o conclamava a prestar o concurso vestibular para o Curso de Pedagogia em um Campus da UFMT, iniciando o curso na modalidade parcelada em 1997. A pesquisadora, por opção, mas com todo o apoio de seus pais, ingressou no ano de 1996 na Faculdade de Educação Física da UFMT. Iniciam então o percurso relacionado à formação inicial de professores.

Segundo Edmunson (1990) refere-se: 
Research, Society and Development, v. 9, n. 11, e1289119665, 2020

(CC BY 4.0) | ISSN 2525-3409 | DOI: http://dx.doi.org/10.33448/rsd-v9i11.9665

[...] a necessidade de que a Formação de professores contribua para que os professores em formação se formem como pessoas, consigam compreender a sua responsabilidade no desenvolvimento da escola e adquiram uma atitude reflexiva acerca do seu ensino. (Edmunson, 1990, apud Marcelo, 2013, p. 80)

Nesse ínterim os pesquisadores tornam-se professores da Educação Básica, na rede estadual de Mato Grosso, "como parte do Contínuo do processo de desenvolvimento profissional do professor” (Vonk, 1993, citado em Marcelo, 2013, p. 112), tornando-se mais tarde professores formadores do Centro de Formação dos profissionais da Educação de Mato Grosso (CEFAPROS), mediante seletivo cujo critério era ser professor efetivo da rede estadual.

Na condição de professores formadores do CEFAPRO, ambos da área de Linguagens, as trajetórias desses pesquisadores se cruzam ao compartilhar espaços de formação muito significativos, como palestras ministradas por Antônio Nóvoa, dentre outros.

Há um novo distanciamento das histórias desses pesquisadores quando iniciam o percurso da Pós-Graduação em Educação e assumem novos percursos profissionais, passando um a atuar no Instituto Federal de Educação e o outro na Formação Inicial de Professores na Universidade Federal de Mato Grosso.

Neste labor em que linguisticamente vieram inventando maneiras de fazer, modos de ser, criando mundos e, por vezes, os desconstruindo, as realidades históricas, inscrevem-se, muito frequentemente, por meio da experiência do limite e da possibilidade em uma corrente vivencial, marcada pela fusão de anterioridade e posterioridade, como um continuum de vivências. De modo que, se sustentam, muito provisoriamente, nestas realidades, aí onde dão expressão a si mesmos, se reencontraram e optaram por conceber junto o texto que ora vos apresentam.

Esse encontro se deu no Programa de Pós-Graduação em Educação, em nível de doutorado, na disciplina optativa de Docência no Ensino Superior, momento em que outras construções se tornaram possíveis.

\section{Percursos de Pesquisa}

Desde a perspectiva aventada o perguntar que se move no horizonte que se lhe apresenta aos pesquisadores, autores deste texto se inscreve histórica, social e epistemologicamente nas trajetórias tanto do pesquisador quanto da pesquisadora. Neste sentido, o fato de ter atuado como professor-formador de Língua Portuguesa no CEFAPRO de Cuiabá, presumivelmente contingenciou o leque de possibilidades de escolha e interferiu fortemente na delimitação do 
tema a ser investigado, bem como na formulação do problema da pesquisa, externada nos seguintes termos: Como professores (as) principiantes vêm experienciando nos respectivos contextos de trabalho as relações entre conhecimentos, aprendizagens/interpessoalidades e, que dimensões deste experienciar sinalizam como sendo significativas?

Da mesma forma, é possível ver nas escolhas da pesquisadora sua trajetória histórica, social, profissional, revelada nas suas intenções de pesquisa, por meio da tentativa de compreender como os professores de Educação Física em início de carreira, transformam suas experiências formativas em algo a ser ensinado, no seu percurso de desenvolvimento profissional e construção da identidade profissional, problematizada a partir dos questionamentos: como os professores de Educação Física em início de carreira transformam suas experiências formativas em algo a ser ensinado? De que maneira incorporam as experiências da formação em suas rotinas pedagógicas? Como transformam suas experiências, seus saberes em objetos de ensino? De que forma a ação pedagógica é influenciada pelas características pessoais e pelo percurso formativo de cada professor? Como o professor constrói sua identidade para além das atividades de ensino que planeja e executa? Como o professor constrói suas redes profissionais e se engajam e compreendem a formação continuada? Porque se tornou o professor que ele é hoje?

As similitudes nos problemas de pesquisa que, atualmente movem o perguntar dos pesquisadores, atestam a influência dos contextos de atuação na conformação tanto das trajetórias de formação quanto nos percursos pessoais. Não tivessem vivenciado contextos próximos tanto no âmbito da formação em uma mesma instituição (UFMT), quanto do desenvolvimento profissional em escolas da Rede Estadual, bem como nos meandros do CEFAPRO, e sequer cogitariam a possibilidade do diálogo inicial que se estabeleceu entre o pesquisador e a pesquisadora, quando aquela burilava as ideias e perscrutava no horizonte a problematização da investigação que levaria a cabo no Doutorado em Educação. Desta e nesta conversação começam a identificar confluências, nas quais os caminhos teórico-metológicos que ambos vem perfazendo, abraçam-se.

Na busca de compor sentidos partilhados neste experienciar juntos, o pesquisador e a pesquisadora vêm constituindo modos pensar, no bojo dos quais a formação docente é compreendida como uma das etapas do desenvolvimento profissional, este por sua vez, remete a um continuиm em que as dimensões pessoais e profissionais, institucionais, organizacionais, contextuais, estão implicadas e se influenciam mutuamente (Marcelo, 1999; 2012; Day, 2005).E, conforme as investigações avançam, mais o relacional sustentado ontologicamente na 
e pela linguagem, como instância em que se torna factível experienciar experiências, se lhes apresenta como ponto fulcral na pesquisas em Educação.

Decorre deste fato a percepção de que para compreender os sentidos sinalizados por meio das vivências marcadas nas trajetórias daqueles que participam das respectivas investigações, conceber a formação como etapa do desenvolvimento profissional docente é fundamental. Por outro lado, entender e situar a carreira docente em algum momento deste desenvolvimento, pressupõe um espaço tridimensional: pessoal e social (interação); passado, presente e futuro (continuidade); combinados à noção de lugar (situação). Tridimensionalidade que faculta investigar introspectiva e extrospectivamente, retrospectiva e prospectivamente (Clandinnin; Connelly, 2011)

Assim, fazendo-se pesquisadores, fazem-se também professores e reencontram-se num percurso que teve como palco de formação e partilhas a disciplina de Docência no Ensino Superior, no Programa de Pós-Graduação em Educação do Programa de Pós-Graduação em Educação da UFMT.

\section{A Docência no Ensino Superior: Refazendo o Percurso de Construção da Identidade Docente}

Ao serem/fazerem-se professores, os pesquisadores fizeram-se também sujeitos de diálogo e de partilhas, tendo suas trajetórias marcadas por encontros, distanciamentos, dentre os quais foi possível perceber espaços compartilhados de formação. Nessa perspectiva, a disciplina de Docência no Ensino Superior, do Programa de Pós-Graduação em Educação, se consolidou como mais um espaço privilegiado de formação dos pesquisadores e de novas partilhas.

A disciplina foi pautada por um percurso que evidenciou a construção de uma identidade docente para o Ensino Superior, que pode ser conferido a partir de sua ementa:

A sociedade e o ensino superior, a expansão, os avanços, a responsabilidade social e o compromisso com o desenvolvimento sustentável da sociedade. Políticas de educação superior e os reflexos no trabalho docente. Estudo das dimensões humana, política, social e as relações com a ação de ensinar e aprender no ambiente educacional e de formação profissional. A sala de aula e a ação de ensinar e aprender como espaço de produção de conhecimento e crescimento coletivo, marcada pela relação entre professor e aluno, compreendida como uma prática social. As tecnologias educacionais como ferramentas do trabalho docente. (PPGE/UFMT, 2016) 
Research, Society and Development, v. 9, n. 11, e1289119665, 2020

(CC BY 4.0) | ISSN 2525-3409 | DOI: http://dx.doi.org/10.33448/rsd-v9i11.9665

As experiências anteriores foram fundamentais para reafirmar os compromissos éticos, políticos e estéticos que cabem ao ensino superior e a educação formal, como um todo. Do mesmo modo, as leituras mediadas por vivas conversações ensejaram aos autores deste ensaio a oportunidade de expandir o pensar, bem como as redes relacionais essenciais ao andamento das pesquisas em que se encontram envolvidos e ao desenvolvimento identitário docente, posto que

É preciso entender o conceito de identidade docente como uma realidade que evolui e se desenvolve tanto pessoal como coletivamente. A identidade não é algo que se possua, mas sim algo que se desenvolve durante a vida. A identidade não é um atributo fixo para uma pessoa, e sim um fenômeno relacional. O desenvolvimento da identidade acontece no terreno do intersubjetivo e se caracteriza como um processo evolutivo, um processo de interpretação de si mesmo como pessoa dentro de determinado contexto. (García, 2009, p. 112)

Assim, é importante ressaltar que tanto os diálogos encetadas com os autores selecionados pelo professor de Didática do Ensino Superior, de Chauí (2001) a Severino (2012;2013); de Pimenta (2010) a Gil (2012); numerosos autores cruzaram os horizontes que os pesquisadores perspectivam e contribuíram, por meio de interações dialógicas, para a continuidade da construção de um olhar demorado sobre a Educação no Ensino Superior, por conseguinte, para a elaboração de um ver articulado sobre os próprios projetos de pesquisa; o ver que

[...] é como um ler articulado daquilo que lá está, de muita coisa que lá está, ele ao mesmo tempo desvia a vista, de maneira que para o olhar já não está mais lá; da mesma forma porém, também guiado por suas antecipações 'olha para dentro' e vê o que lá nem está. (Gadamer,1997, p. 160).

Desde este prisma é factível compreender que toda a interpretação curricular, seja ela do ensino ou da formação, depende da construção da identidade pessoal e profissional dos professores, aqui também dos pesquisadores (Day, 2001). Nesse sentido todos os conhecimentos devem estar diretamente ligados às necessidades pessoais, profissionais e até dos seus propósitos morais, o que faz dos espaços compartilhados de formação ainda mais imprescindíveis. 


\section{Considerações Finais}

Constituir-se como Doutor/Doutora, pressupõe a construção de trajetórias nas quais a ação de pesquisar se inscreva no percurso pessoal dos sujeitos que a perfazem. Percurso e trajetórias erigidos nos meandros relacionais, epistêmicos, identitários. Portanto, para sagrar-se Doutor/Doutora, porquanto é mister, ir além das formalidades acadêmicas e rituais de titulação.

O percurso que atravessa essas trajetórias dá relevância a ideia de que a formação de professores deve dar especial atenção à pessoa do professor

A formação de professores deve dedicar uma atenção especial às dimensões pessoais da profissão docente, trabalhando essa capacidade de relação e de comunicação que define o tacto pedagógico. Ao longo dos últimos anos, temos dito (e repetido) que o professor é a pessoa, e que a pessoa é o professor. Que é impossível separar as dimensões pessoais e profissionais. Que ensinamos aquilo que somos e que, naquilo que somos, se encontra muito daquilo que ensinamos. Que importa, por isso, que os professores se preparem para um trabalho sobre si próprios, para um trabalho de autoreflexão e de auto-análise. (Nóvoa, 2009, p.38)

A escrita conjunta deste texto prefigura o alcance e relevância de se promover desde dentro da Academia espaços e tempos, nos quais os pesquisadores se encontrem, reconheçamse e possam partilhar, por meio de conversações autênticas, perspectivas de investigação, saberes e desconhecimentos, ideais, projetos e sonhos. Encontros que entrelacem o ser gente com ser fundante a se mover no âmbito das pesquisas e do conhecer. A disciplina de Didática do Ensino Superior, as vivências nos meandros dela facultadas, permite vicejar que tais encontros são possíveis, necessários, urgentes.

Por fim, é pertinente ao finalizar este ensaio, trazer à luz a compreensão que atravessou este ensaio, a máxima citada pelo psicólogo e pedagogo, Carl Rogers, nos anos 60, de que nós não nascemos pessoas; nós tornamo-nos pessoas; nós fazemo-nos, construímo-nos como pessoas, oportunamente trazida para dentro da profissão docente ao conceber que não se nasce professor, vai-se fazendo professor ao longo de uma vida, do desenvolvimento profissional do ser, que é um desenvolvimento profissional longo. (Nóvoa, 2016) 


\section{Referências}

Clandinin, D. J., \& Connelly, F. M. Pesquisa Narrativa: experiências e história na pesquisa qualitativa. Tradução: Grupo de Pesquisa Narrativa e Educação de Professores ILEEL/UFU. Uberlândia: EDUFU, 2011.

Day, C. Desenvolvimento profissional de professores: os desafios da aprendizagem permanente. Porto Editora: Porto, Portugal, 2001.

Day, C. Formar Docentes: Cómo, cuándo y en qué condiciones aprende el profesorado. Narcea, Madrid: 2005.

Gadamer, H-G. Verdade e método. Tradução de Flávio Paulo Meurer. Petrópolis, RJ. Ed. Vozes, 1997.

Gonçalves, J. A. M. A carreira das professoras do ensino primário. In: Nóvoa, A. (Org.). Vidas de professores. Porto Editora, Porto, Portugal, 2013.

Huberman, M. O ciclo de vida profissional dos professores. In: Nóvoa, A. (Org.). Vidas de professores. Porto Editora, Porto, Portugal, 2013.

Ibiapina, I. M. L. M. Pesquisa colaborativa: investigação, formação e produção de conhecimentos. Liber Livro: Brasília, 2008.

Marcelo, C. Formação de professores: Para uma mudança educativa. Porto-Portugal:Porto editora, 1999.

Marcelo, C. G. Formação de professores: para uma mudança educativa. Porto Editora, Porto, Portugal, 2013.

Marcelo, A identidade docente: constantes e desafios in Revista Brasileira de pesquisa sobre formação de professores, 01(01).

Nóvoa, A. Professores Imagens do futuro presente. EDUCA, Lisboa, 2009 
Nóvoa, A. Os professores e as histórias da sua vida. In: Nóvoa, A. (Org.). Vidas de professores. Porto Editora, Porto, Portugal, 2013.

Nóvoa, A. Diálogos entre formação de professores e as pesquisas sobre educação na atualidade. Cuiabá, UFMT, 2016. (Conferência)

Zeichner, K. Os professores como prático reflexivo. In: Zeichner, K. A Formação reflexiva de professores: ideias e práticas. Educa, Lisboa,1993.

\section{Porcentagem de contribuição de cada autor no manuscrito}

Edson Gomes Evangelista - 50\%

Luciane de Almeida Gomes - 50\% 